\title{
Impact of Prioritizing Elderly and High-risk Individuals During COVID-19 Vaccine Allocation
}

\author{
Buse Eylul Oruc \\ Georgia Institute of Technology \\ Akane Fujimoto \\ Georgia Institute of Technology \\ Robert Breiman \\ Emory University \\ Pinar Keskinocak ( $\sim$ pinar@isye.gatech.edu ) \\ Georgia Institute of Technology
}

\section{Research Article}

Keywords: agent-based disease modeling, COVID19, vaccine prioritization, elderly prioritization

Posted Date: October 7th, 2021

DOI: https://doi.org/10.21203/rs.3.rs-944201/v1

License: (c) (i) This work is licensed under a Creative Commons Attribution 4.0 International License. Read Full License 


\section{Abstract}

Background

The prioritization of vaccine eligibility for different subpopulations is an important decision to curb spread and severe outcomes of epidemic infectious diseases for which vaccines become available. Using COVID-19 as a prototype, this study evaluates the public health impact of various vaccine prioritization schemes of elderly and high-risk individuals with different vaccination start dates and rollout speeds.

Methods

An agent-based simulation model was adapted and used to project the number of infections, hospitalizations, and deaths under various vaccination start dates, rollout speeds, and prioritization schemes, including (A)no prioritization, (B)two-staged prioritization of elderly population, and (C)multi-staged prioritization of elderly and then high-risk population. The study period was February $18^{\text {th }}$, 2020 -June $1^{\text {st }}, 2021$, and the state of Georgia was used as a case study.

Results

The relative effectiveness of the prioritization schemes depends on the outcome considered, as well as the vaccination start date, prioritized subpopulations, and rollout speed. Having no prioritization results in the fewest infections and hospitalizations in most scenarios; however, it yields the highest number of deaths. Prioritizing the elderly and then high-risk individuals results in the fewest overall and high-risk deaths in most scenarios.

Conclusions

Having no vaccine prioritization, i.e., opening vaccination to every adult regardless of age, simplifies vaccine rollout and reduces the infection spread but results in a higher number of deaths, especially among the elderly and high-risk populations. Prioritizing the elderly, then high-risk patients, as opposed to prioritizing only the elderly provides benefit regarding severe outcomes; however, such assumed benefits need to be counterbalanced with challenges in communicating eligibility and criteria and in distributing vaccines effectively and equitably which could result in suboptimal vaccine uptake and coverage, including among people within subpopulations at disproportionate risk of illness, hospitalization and death, of particular concern during periods of high incidence, severe disease, and death.

\section{Background}

The COVID-19 vaccine rollout has challenged decision-makers all around the U.S. with the decision when and how to prioritize subpopulations while ensuring vaccines do not go unused [1]. In the U.S., there has been a variety of prioritization guidelines. For example, the Department of Health and Human Services recommended prioritizing first healthcare workers and then prioritizing all people ages 65 and above and those under 65 with high-risk medical conditions while the CDC Advisory Committee on Immunization Practices recommended prioritizing healthcare workers (regardless of age, co-morbidities, or risk of exposure to the virus), long-term care residents, and all people ages 75+ [2, 3]. In addition, the National Academies of Sciences, Engineering, and Medicine put forward a framework for equitable allocation of vaccine allocation to assist policymakers considering individuals, occupations, and populations at higher risk [4]. While some experts advocated for a simple, uniform prioritization scheme based on age because it would be easy to communicate and could improve distribution, states have developed and followed local vaccine prioritization schemes with staggered eligibility requirements $[1,5-7]$.

Vaccine prioritization schemes under limited supply have been studied in the literature for outbreaks such as H1N1 influenza pandemic [8] and Ebola [9]. However, disease characteristics of COVID-19 make adoption of pre-existing prioritization frameworks suboptimal in mitigating the severe outcomes and the spread of the pandemic. Several studies have discussed and evaluated the health outcomes and equity implications of the COVID-19 vaccine prioritization schemes prioritizing essential workers, elderly, historically marginalized populations [10-15]. The findings suggested that prioritizing elderly had the greatest impact on COVID-19 mortality, whereas prioritizing individuals with high transmission risk had the greatest impact in reducing spread of the disease [1115]. These studies highlighted the need for evaluating the effectiveness of two-staged and multi-staged prioritization of elderly and 
high-risk populations in mitigating the spread of the pandemic and adverse outcomes. We set out to evaluate vaccine prioritization schemes, including (A) no prioritization, (B) two-staged prioritization of elderly population, and (C) multi-staged prioritization of elderly and then high-risk population with different vaccination start dates and rollout speeds to understand their effectiveness in mitigating the spread of the pandemic.

In this study, we compared the projected number of infections, hospitalizations, and deaths due to COVID-19 when there is no prioritization in place, elderly are prioritized, and elderly and high-risk individuals are prioritized with different vaccination start dates and rollout speeds.

\section{Methods}

\section{Scenario Descriptions}

The scenarios modeled study three prioritization schemes:

1. No prioritization: all people of age $\geq 20$ are eligible (i.e., no prioritization);

2. Two-staged prioritization: all people of age $\geq 65$ are eligible, then all people of age $\geq 20$ (only elderly is prioritized);

3. Multi-staged prioritization: all people of age $\geq 65$ are eligible, then high-risk people of age $\geq 20$, then remaining people age $\geq 20$ (i.e., elderly and then high-risk individuals are prioritized).

Being high-risk (for hospitalization and death) was defined as having any of the following conditions: diabetes, heart disease, chronic obstructive pulmonary disease (COPD), obesity, and kidney disease. Although intial emergency authorization of COVID-19 vaccine considered all people of age $\geq 18$ as vaccinable, as the population in the simulation broken down to ages 0-9, 10-19, 20-64, and $\geq 65$, this study considered all people of age $\geq 20$ as vaccinable.

The base scenario considers vaccine efficacy of $90 \%$ and a vaccination start date of December 16 th, 2020 , which corresponds to approximately ten months after the first infection was recorded in the simulation, as was the case for the COVID-19 vaccine deployment in the U.S. [16], with a rollout speed of 1 (i.e., each week, $1 \%$ of the total population is vaccinated). Additional scenarios with rollouts speeds of 2 and 3 (i.e., each week, $2 \%$ or $3 \%$, respectively, of the population, is vaccinated) and a vaccination start on September 16th, 2020, which corresponds to an earlier rollout three months before the actual deployment, are also considered.

For ease of reporting, the scenarios are labeled by their prioritization scheme (no prioritization, two-staged prioritization, or multistaged prioritization), vaccination start date (Early = September 16th, 2020 and Actual = December 16th, 2020), and rollout speed (1, 2 , and $3=1 \%, 2 \%$, and $3 \%$ of the population vaccinated each week).

\section{Modeling case projection}

An agent-based simulation model with heterogeneous population mixing was adapted and utilized to predict the spread of COVID-19 geographically and over time [17]. The model was populated with the population-related data, including demographic information, high risk conditions, work travel flows, and household statistics in the state of Georgia from publicly available databases (U.S. Census Bureau American Community Survey [https://www.census.gov/newsroom/press-kits/2019/acs-1year.html], U.S. Census Bureau Census Transportation Planning Products [https://ctpp.transportation.org/ctpp-data-set-information/]). The population in the simulation is reflective of the population characteristics of Georgia. The model captured the progression of the disease in an individual with a variant of a Susceptible-Exposed-Infected-Recovered (SEIR) model, and the disease spread with modeling interactions within households, schools, workplaces, and communities. Each individual was assumed to be in one state at a given time, such as susceptible, exposed, transitioning (pre-symptomatic), infected-asymptomatic, infected-symptomatic, hospitalized, recovered, or dead. Diabetes, heart disease, chronic obstructive pulmonary disease (COPD), obesity, and kidney disease were included as risk factors for death, conditional on an individual's age and county as derived from statewide prevalence data $[18,19]$. The model also incorporated non-pharmaceutical interventions such as school closures, shelter-in-place, voluntary quarantine, and universal requirements for the use of face coverings/masks, with different compliance rates over time, in line with what has been observed in the state of Georgia. A more detailed model description can be found in [17], and model parameters and assumptions are provided in Supplementary Section A, Additional File 1. In this study, we also utilized case and vaccination data from publicly available databases (Georgia Department of Public Health COVID-19 Daily Status Report [https://dph.georgia.gov/covid-19-daily-

Page $3 / 10$ 
status-report] and Georgia Department of Public Health Covid-19 Vaccine Dashboard

[https://experience.arcgis.com/experience/3d8eea39f5c1443db1743a4cb8948a9c]) for calibration of assumptions.

The study period included February 18th, 2020, to June 1st, 2021. The population in the simulation included children, adults, and the elderly stratified by age groups: $0-9,10-19,20-64$, and $65+$ in the state of Georgia. All results presented in this study are the averages of 30 replications (for each scenario) of the agent-based simulation model runs.

\section{Outcome Measures}

The outcome measures reported for the time horizon of the study include:

- Cumulative infections: cumulative number of (sub)population infected (including asymptomatic infections).

- Cumulative hospitalizations: cumulative number of (sub)population who hospitalized due to COVID-19.

- Cumulative deaths: cumulative number of (sub)population who died due to COVID-19.

\section{Results}

We report the projected number of infections, hospitalizations, and deaths for the outcomes period (from the vaccination start date to the end date of the study period) under the various vaccination prioritization schemes, as displayed in Table 1. Additionally, we report the differences and percentage changes in the outcomes when comparing the prioritization schemes, as seen in Table 2. 
Table 1 Outcome measures from the vaccination start date across scenarios.

\begin{tabular}{|c|c|c|c|c|c|c|c|c|c|c|c|}
\hline \multirow[b]{2}{*}{$\begin{array}{l}\text { Vaccine } \\
\text { Start }\end{array}$} & \multirow[b]{2}{*}{ Group } & \multirow[b]{2}{*}{$\begin{array}{l}\text { Rollout } \\
\text { Speed }\end{array}$} & \multicolumn{3}{|l|}{ Infections } & \multicolumn{3}{|c|}{ Hospitalizations } & \multicolumn{3}{|c|}{ Deaths } \\
\hline & & & A & B & $\mathrm{C}$ & A & B & C & A & B & $\mathrm{C}$ \\
\hline \multirow{9}{*}{$\begin{array}{l}\text { Dec. } \\
16 \text { th, } \\
2020 \\
\text { (Actual) }\end{array}$} & Overall & \multirow[t]{3}{*}{1} & 1381272 & 1555431 & 1546644 & 33584 & 35546 & 35346 & 5994 & 5583 & 5601 \\
\hline & $\begin{array}{l}\text { High- } \\
\text { risk }\end{array}$ & & 379888 & 412649 & 408295 & 24426 & 25409 & 25269 & 5206 & 4855 & 4886 \\
\hline & $\begin{array}{l}\text { Non- } \\
\text { high- } \\
\text { risk }\end{array}$ & & 1001385 & 1142781 & 1138348 & 9158 & 10137 & 10078 & 788 & 729 & 715 \\
\hline & Overall & \multirow[t]{3}{*}{2} & 1139651 & 1319601 & 1298870 & 27731 & 29227 & 28480 & 5089 & 4202 & 4157 \\
\hline & $\begin{array}{l}\text { High- } \\
\text { risk }\end{array}$ & & 308036 & 335931 & 319729 & 20287 & 20597 & 19762 & 4444 & 3608 & 3558 \\
\hline & $\begin{array}{l}\text { Non- } \\
\text { high- } \\
\text { risk }\end{array}$ & & 831615 & 983670 & 979141 & 7444 & 8631 & 8717 & 645 & 594 & 599 \\
\hline & Overall & \multirow[t]{3}{*}{3} & 933536 & 1097199 & 1074260 & 23033 & 24046 & 22633 & 4295 & 3474 & 3265 \\
\hline & $\begin{array}{l}\text { High- } \\
\text { risk }\end{array}$ & & 249065 & 271716 & 245497 & 16768 & 16791 & 15277 & 3757 & 2975 & 2768 \\
\hline & $\begin{array}{l}\text { Non- } \\
\text { high- } \\
\text { risk }\end{array}$ & & 684471 & 825483 & 828763 & 6265 & 7255 & 7356 & 538 & 499 & 497 \\
\hline \multirow{9}{*}{$\begin{array}{l}\text { Sep. } \\
16 \text { th, } \\
2020 \\
\text { (Early) }\end{array}$} & Overall & \multirow[t]{3}{*}{1} & 1031390 & 1525704 & 1532060 & 23349 & 30066 & 28965 & 3960 & 3645 & 3488 \\
\hline & $\begin{array}{l}\text { High- } \\
\text { risk }\end{array}$ & & 273167 & 375341 & 343275 & 16786 & 20712 & 19200 & 3429 & 3107 & 2957 \\
\hline & $\begin{array}{l}\text { Non- } \\
\text { high- } \\
\text { risk }\end{array}$ & & 758223 & 1150363 & 1188785 & 6563 & 9355 & 9765 & 531 & 538 & 530 \\
\hline & Overall & \multirow[t]{3}{*}{2} & 498106 & 666753 & 658103 & 11551 & 13438 & 12171 & 2052 & 1772 & 1669 \\
\hline & $\begin{array}{l}\text { High- } \\
\text { risk }\end{array}$ & & 129421 & 160745 & 127426 & 8334 & 9227 & 7647 & 1799 & 1521 & 1393 \\
\hline & $\begin{array}{l}\text { Non- } \\
\text { high- } \\
\text { risk }\end{array}$ & & 368684 & 506008 & 530678 & 3218 & 4211 & 4524 & 253 & 251 & 276 \\
\hline & Overall & \multirow[t]{3}{*}{3} & 358185 & 434652 & 441524 & 8456 & 9081 & 8452 & 1586 & 1316 & 1248 \\
\hline & $\begin{array}{l}\text { High- } \\
\text { risk }\end{array}$ & & 90662 & 103598 & 82414 & 6076 & 6285 & 5317 & 1369 & 1127 & 1040 \\
\hline & $\begin{array}{l}\text { Non- } \\
\text { high- } \\
\text { risk }\end{array}$ & & 267523 & 331054 & 359110 & 2380 & 2796 & 3135 & 217 & 190 & 208 \\
\hline
\end{tabular}

Table 2: Difference and percentage change in outcome measures across scenarios. 


\begin{tabular}{|c|c|c|c|c|c|c|c|c|c|c|c|}
\hline \multirow[b]{2}{*}{$\begin{array}{c}\text { Vaccine } \\
\text { Start }\end{array}$} & \multirow[b]{2}{*}{ Group } & \multirow[b]{2}{*}{$\begin{array}{l}\text { Rollout } \\
\text { Speed }\end{array}$} & \multicolumn{3}{|c|}{$\begin{array}{c}\Delta_{A B^{\mathrm{d}}} \\
\text { Difference }(\% \text { change) }\end{array}$} & \multicolumn{3}{|c|}{$\begin{array}{c}\Delta_{A C} \\
\text { Difference (\% change) }\end{array}$} & \multicolumn{3}{|c|}{$\begin{array}{c}\Delta_{B C} \\
\text { Difference }(\% \text { change })\end{array}$} \\
\hline & & & $\begin{array}{c}\text { nfection } \\
s\end{array}$ & Hosp. & eaths & $\begin{array}{c}\text { Infection } \\
\mathbf{s}\end{array}$ & Hosp. & ths & $\begin{array}{c}\text { Infection } \\
5\end{array}$ & p. & -3 \\
\hline \multirow{9}{*}{$\begin{array}{c}\text { Dec. } \\
16 \text { th, } \\
2020 \\
\text { (Actual) }\end{array}$} & & \multirow{3}{*}{1} & $\begin{array}{l}174159 \\
(12.61) \\
\end{array}$ & $\begin{array}{r}1962 \\
(5.84) \\
\end{array}$ & $\begin{array}{r}-411 \\
(-6.85) \\
\end{array}$ & $\begin{array}{l}165372 \\
(11.97) \\
\end{array}$ & $\begin{array}{r}1762 \\
(5.25) \\
\end{array}$ & $\begin{array}{r}-393 \\
(-6.55) \\
\end{array}$ & $\begin{array}{r}-8787 \\
(-0.56) \\
\end{array}$ & $\begin{array}{r}-200 \\
(-0.56) \\
\end{array}$ & $\begin{array}{r}18 \\
(0.32) \\
\end{array}$ \\
\hline & High & & $\begin{array}{l}32761 \\
(8.62)\end{array}$ & $\begin{array}{r}983 \\
(4.03) \\
\end{array}$ & $\begin{array}{r}-351 \\
(-6.74) \\
\end{array}$ & $\begin{array}{r}28407 \\
(7.48)\end{array}$ & $\begin{array}{r}843 \\
(3.45) \\
\end{array}$ & $\begin{array}{r}-320 \\
(-6.14) \\
\end{array}$ & $\begin{array}{r}-4354 \\
(-1.06)\end{array}$ & $\begin{array}{r}-140 \\
(-0.55) \\
\end{array}$ & $\begin{array}{r}31 \\
(0.65) \\
\end{array}$ \\
\hline & Non-high-risk & & $\begin{array}{l}141396 \\
(14.12)\end{array}$ & $\begin{array}{r}979 \\
(10.69)\end{array}$ & $\begin{array}{r}-59 \\
(-7.53)\end{array}$ & $\begin{array}{l}136963 \\
(13.68)\end{array}$ & $\begin{array}{r}920 \\
(10.04)\end{array}$ & $\begin{array}{r}-73 \\
(-9.22)\end{array}$ & $\begin{array}{r}-4433 \\
(-0.39)\end{array}$ & $\begin{array}{r}-59 \\
(-0.59)\end{array}$ & $\begin{array}{r}-14 \\
(-1.83)\end{array}$ \\
\hline & Overall & \multirow{3}{*}{2} & $\begin{array}{l}179950 \\
(15.79) \\
\end{array}$ & $\begin{array}{l}1496 \\
(5.4)\end{array}$ & $\begin{array}{r}-887 \\
(-17.43) \\
\end{array}$ & $\begin{array}{l}159219 \\
(13.97) \\
\end{array}$ & $\begin{array}{r}749 \\
(2.7) \\
\end{array}$ & $\begin{array}{r}-932 \\
(-18.32) \\
\end{array}$ & & $\begin{array}{r}-747 \\
(-2.56) \\
\end{array}$ & $\begin{array}{r}-45 \\
(-1.08) \\
\end{array}$ \\
\hline & High & & $\begin{array}{r}27895 \\
(9.06) \\
\end{array}$ & $\begin{array}{r}310 \\
(1.53) \\
\end{array}$ & $\begin{array}{r}-836 \\
(-18.81) \\
\end{array}$ & $\begin{array}{r}11693 \\
(3.8) \\
\end{array}$ & $\begin{array}{r}-525 \\
(-2.59) \\
\end{array}$ & $\begin{array}{r}-886 \\
(-19.95) \\
\end{array}$ & $\begin{array}{r}-16202 \\
(-4.82) \\
\end{array}$ & $\begin{array}{r}-835 \\
(-4.05) \\
\end{array}$ & $\begin{array}{r}-50 \\
(-1.4) \\
\end{array}$ \\
\hline & Non- & & $\begin{array}{l}152055 \\
(18.28) \\
\end{array}$ & $\begin{array}{r}1187 \\
(15.95) \\
\end{array}$ & $\begin{array}{r}-51 \\
(-7.91) \\
\end{array}$ & $\begin{array}{l}147526 \\
(17.74) \\
\end{array}$ & $\begin{array}{r}1273 \\
(17.11) \\
\end{array}$ & $\begin{array}{r}-46 \\
(-7.08) \\
\end{array}$ & $\begin{array}{r}-4529 \\
(-0.46) \\
\end{array}$ & $\begin{array}{l}86 \\
(1) \\
\end{array}$ & $\begin{array}{r}5 \\
(0.9) \\
\end{array}$ \\
\hline & Ove & \multirow{3}{*}{3} & $\begin{array}{l}163663 \\
(17.53) \\
\end{array}$ & $\begin{array}{l}1013 \\
(4.4) \\
\end{array}$ & $\begin{array}{r}-821 \\
(-19.11) \\
\end{array}$ & $\begin{array}{l}140724 \\
(15.07) \\
\end{array}$ & $\begin{array}{r}-400 \\
(-1.74) \\
\end{array}$ & $\begin{array}{r}-1030 \\
(-23.98) \\
\end{array}$ & $\begin{array}{r}-22939 \\
(-2.09) \\
\end{array}$ & $\begin{array}{r}-1413 \\
(-5.88) \\
\end{array}$ & $\begin{array}{r}-209 \\
(-6.02) \\
\end{array}$ \\
\hline & High & & $\begin{array}{l}22651 \\
(9.09) \\
\end{array}$ & $\begin{array}{r}23 \\
(0.14) \\
\end{array}$ & $\begin{array}{r}-782 \\
(-20.82) \\
\end{array}$ & $\begin{array}{r}-3568 \\
(-1.43) \\
\end{array}$ & $\begin{array}{r}-1491 \\
(-8.9)\end{array}$ & $\begin{array}{r}-989 \\
(-26.33) \\
\end{array}$ & $\begin{array}{l}-26219 \\
(-9.65) \\
\end{array}$ & $\begin{array}{r}-1514 \\
(-9.02)\end{array}$ & $\begin{array}{r}-207 \\
(-6.96) \\
\end{array}$ \\
\hline & s & & $\begin{array}{r}141012 \\
(20.6) \\
\end{array}$ & $\begin{array}{r}990 \\
(15.81) \\
\end{array}$ & $\begin{array}{r}-39 \\
(-7.19) \\
\end{array}$ & $\begin{array}{l}144292 \\
(21.08)\end{array}$ & $\begin{array}{r}1091 \\
(17.41) \\
\end{array}$ & $\begin{array}{r}-41 \\
(-7.56) \\
\end{array}$ & $\begin{array}{l}3280 \\
(0.4)\end{array}$ & $\begin{array}{r}101 \\
(1.39) \\
\end{array}$ & $\begin{array}{r}-2 \\
(-0.4) \\
\end{array}$ \\
\hline \multirow{8}{*}{$\begin{array}{l}\text { Sep. } \\
16 \text { th, } \\
2020 \\
\text { (Early) }\end{array}$} & Overall & \multirow{3}{*}{1} & $\begin{array}{l}494314 \\
(47.93) \\
\end{array}$ & $\begin{array}{r}6717 \\
(28.77) \\
\end{array}$ & $\begin{array}{r}-315 \\
(-7.96) \\
\end{array}$ & $\begin{array}{l}500670 \\
(48.54) \\
\end{array}$ & $\begin{array}{r}5616 \\
(24.05) \\
\end{array}$ & $\begin{array}{r}-472 \\
(-11.93) \\
\end{array}$ & $\begin{array}{r}6356 \\
(0.42) \\
\end{array}$ & $\begin{array}{r}-1101 \\
(-3.66) \\
\end{array}$ & $\begin{array}{r}-157 \\
(-4.31) \\
\end{array}$ \\
\hline & High & & $\begin{array}{r}102174 \\
(37.4) \\
\end{array}$ & $\begin{array}{r}3926 \\
(23.39) \\
\end{array}$ & $\begin{array}{r}-322 \\
(-9.39) \\
\end{array}$ & $\begin{array}{r}70108 \\
(25.66) \\
\end{array}$ & $\begin{array}{r}2414 \\
(14.38) \\
\end{array}$ & $\begin{array}{r}-472 \\
(-13.75) \\
\end{array}$ & $\begin{array}{r}-32066 \\
(-8.54) \\
\end{array}$ & $\begin{array}{r}-1512 \\
(-7.3)\end{array}$ & $\begin{array}{r}-150 \\
(-4.81) \\
\end{array}$ \\
\hline & & & $\begin{array}{l}392140 \\
(51.72) \\
\end{array}$ & $\begin{array}{r}2792 \\
(42.53) \\
\end{array}$ & $\begin{array}{r}7 \\
(1.25) \\
\end{array}$ & $\begin{array}{l}430562 \\
(56.79)\end{array}$ & $\begin{array}{r}3202 \\
(48.78) \\
\end{array}$ & $\begin{array}{r}-1 \\
(-0.19) \\
\end{array}$ & $\begin{array}{l}38422 \\
(3.34)\end{array}$ & $\begin{array}{r}410 \\
(4.39) \\
\end{array}$ & $\begin{array}{r}-8 \\
(-1.43) \\
\end{array}$ \\
\hline & Overall & & $\begin{array}{l}168647 \\
(33.86) \\
\end{array}$ & $\begin{array}{r}1887 \\
(16.33) \\
\end{array}$ & $\begin{array}{r}-280 \\
(-13.65) \\
\end{array}$ & $\begin{array}{l}159997 \\
(32.12)\end{array}$ & $\begin{array}{r}620 \\
(5.36) \\
\end{array}$ & $\begin{array}{r}-383 \\
(-18.68) \\
\end{array}$ & $\begin{array}{r}-8650 \\
(-1.3) \\
\end{array}$ & $\begin{array}{r}-1267 \\
(-9.43) \\
\end{array}$ & $\begin{array}{r}-103 \\
(-5.83) \\
\end{array}$ \\
\hline & High & & $\begin{array}{l}31324 \\
(24.2)\end{array}$ & $\begin{array}{r}893 \\
(10.72) \\
\end{array}$ & $\begin{array}{r}-278 \\
(-15.43) \\
\end{array}$ & $\begin{array}{r}-1995 \\
(-1.54) \\
\end{array}$ & $\begin{array}{r}-687 \\
(-8.24) \\
\end{array}$ & $\begin{array}{r}-406 \\
(-22.57) \\
\end{array}$ & $\begin{array}{r}-33319 \\
(-20.73) \\
\end{array}$ & $\begin{array}{r}-1580 \\
(-17.13) \\
\end{array}$ & $\begin{array}{r}-128 \\
(-8.44) \\
\end{array}$ \\
\hline & 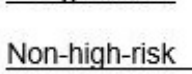 & & $\begin{array}{r}137,324 \\
(37.25) \\
\end{array}$ & $\begin{array}{r}993 \\
(30.87) \\
\end{array}$ & $\begin{array}{r}-2 \\
(-0.92)\end{array}$ & $\begin{array}{r}161,994 \\
(43.94) \\
\end{array}$ & $\begin{array}{r}1,306 \\
(40.61) \\
\end{array}$ & $\begin{array}{r}23 \\
(8.96) \\
\end{array}$ & $\begin{array}{r}24,670 \\
(4.88) \\
\end{array}$ & $\begin{array}{r}313 \\
(7.44) \\
\end{array}$ & $\begin{array}{r}25 \\
(9.97) \\
\end{array}$ \\
\hline & Overall & & $\begin{array}{r}76,467 \\
(21.35) \\
\end{array}$ & $\begin{array}{r}625 \\
(7.39) \\
\end{array}$ & $\begin{array}{r}-270 \\
(-17.02) \\
\end{array}$ & $\begin{array}{r}83,339 \\
(23.27) \\
\end{array}$ & $\begin{array}{r}-4 \\
(-0.05) \\
\end{array}$ & $\begin{array}{r}-338 \\
(-21.31) \\
\end{array}$ & $\begin{array}{r}6,872 \\
(1.58) \\
\end{array}$ & $\begin{array}{r}-629 \\
(-6.93) \\
\end{array}$ & $\begin{array}{r}-68 \\
(-5.17) \\
\end{array}$ \\
\hline & High-risk & & $\begin{array}{r}12936 \\
(14.27)\end{array}$ & $\begin{array}{r}209 \\
(3.45) \\
\end{array}$ & $\begin{array}{r}-242 \\
(-17.7) \\
\end{array}$ & $\begin{array}{r}-8,248 \\
(-9.1)\end{array}$ & $\begin{array}{r}-759 \\
-12.49) \\
\end{array}$ & $\begin{array}{r}-329 \\
(-24.03)\end{array}$ & $\begin{array}{l}-21,184 \\
(-20.45)\end{array}$ & $\begin{array}{r}-968 \\
(-15.41)\end{array}$ & $\begin{array}{r}-87 \\
(-7.69) \\
\end{array}$ \\
\hline
\end{tabular}

Difference and percentage change in the number of cumulative infections, hospitalizations, and deaths between prioritization schemes $A, B$, and $C[1]$. The notation $\Delta_{x y}$ indicates indicates the difference in the outcomes and percentage change from scheme $X$ to scheme $Y$, where a positive or negative number means an increase or decrease in the outcome measured from scheme $X$ to scheme $Y$.

\section{Cumulative infections}

Table 1 shows the projected infections during the outcomes period under the three vaccination schemes. No prioritization yielded the fewest number of infections for all scenarios when considering the overall and non-high-risk population. Within the high-risk population, no prioritization performed the best (fewest infections) in all cases, except when the vaccine start was in December with a rollout speed of 3 (3\% of the population gets vaccinated weekly) and when the vaccine start was in September with rollout speeds of 2 or 3 . In those 3 cases, multi-staged prioritization (prioritization of elderly and then high-risk) performed the best. We observed similar patterns across vaccine prioritization schemes in both vaccine start dates.

Table 2 shows that when comparing no vaccine prioritization to two-staged prioritization of only the elderly and multi-staged prioritization of elderly and high-risk, the prioritization of individuals resulted in a significant increase in infections, ranging up to 500,670 additional infections or up to a 49,37 , and $57 \%$ increase in overall, high-risk, and non-high-risk infections, respectively. When comparing two-staged and multi-staged prioritization, multi-staged prioritization performed better in most of the scenarios. The difference in infections for the overall and non-high-risk population was small (less than $9 \%$ change). However, multi-staged prioritization significantly decreased infections within the high-risk population when the vaccine start was in December with a rollout speed of $3(26,219$ fewer high-risk infections or a $10 \%$ decrease) or when the vaccine start was earlier in September with rollout speeds of 2 or 3 (up to 33,319 fewer high-risk infections or up to a $21 \%$ decrease).

\section{Cumulative Hospitalizations}


No prioritization yielded the lowest overall hospitalizations in all scenarios when the rollout speed is 1 or 2 . Multi-staged prioritization resulted in the lowest overall hospitalizations when the rollout speed is 3 . Within the high-risk population, no prioritization was the best at rollout speed of 1 , while multi-staged prioritization was the best scheme at rollout speeds 2 and 3 for both vaccination start dates.

Similar to the results observed regarding infections, hospitalizations increased when only the elderly are prioritized by two-staged prioritization versus no prioritization. Multi-staged prioritization of elderly and high-risk populations reduced the hospitalizations for the high-risk group when the rollout speeds are 2, and 3 for both vaccinations start dates compared to no prioritization. Multi-staged prioritization performed better than two-staged prioritization for both the overall and high-risk populations with percentage decreases ranging from 1 to $17 \%$ depending on the scenario and up to 1,580 fewer hospitalizations.

\section{Cumulative Deaths}

When evaluating cumulative deaths, two-staged and multi-staged prioritization yielded the fewest number of deaths, while no prioritization yielded the highest number of deaths, contrary to the results observed in infections and hospitalizations. The relative ranking between the performance of two-staged and multi-staged prioritization depends on the vaccine start date, subpopulation evaluated, and rollout speed.

When the vaccine start is in December, and we evaluate overall and high-risk populations, two-staged prioritization yielded the fewest number of deaths with the rollout speed of 1, while multi-staged prioritization performed the best with the rollout speed set to 2 and

3. When the vaccine start is in September, multi-staged prioritization yielded the fewest number of deaths for the overall and high-risk population at all rollout speeds.

When vaccine prioritization is put in place (two-staged or multi-staged), there was a substantial proportionate reduction in deaths, up to 1,030 fewer deaths or up to a $26 \%$ decrease when compared to no prioritization. The multi-staged prioritization of elderly and highrisk populations results in fewer deaths for the overall and high-risk groups compared to when only the elderly are prioritized (up to 209 fewer deaths or up to $6 \%$ and $8 \%$ decrease in the overall and high-risk populations, respectively). The percentage reduction in deaths by including the high-risk population as a priority is more significant when the vaccine start is earlier and the rollout speed is faster.

\section{Discussion}

Desperate situations often call for desperate measures. In the setting of a rapidly emerging epidemic of a new disease or pandemic, there are usually shortages of critical supplies for prevention or treatment, whether they be non-pharmaceutical (like N-95 masks), novel vaccines, or new therapeutics. In such circumstances, priorities are often set for implementing specific interventions. Informing the approach for setting priorities can be critical for reaching specific outcomes.

Our analyses show the impact on infections, hospitalizations, and deaths when vaccine allocation prioritizes the elderly and/or highrisk populations. No prioritization is the best performing strategy at reducing the number of infections in almost all scenarios (up to 500,670 fewer cases when comparing to two-stage and multi-stage prioritization); however, it results in the largest number of deaths. By contrast, multi-staged prioritization of elderly and high-risk individuals is the best performing scheme to reduce the number of deaths. Our analyses comparing no-prioritization and two-staged prioritization follows the findings in the literature [11-13]; however, different from those, we implemented and evaluated multi-staged prioritizion, prioritizing high-risk individuals after vaccinating elderly and found it provides the greatest benefit in reducing COVID-19 mortality.

When evaluating infections in the high-risk population, multi-stage prioritization results in the fewest number of infections at higher implementation rates. When vaccination starts in December with a rollout speed of 3, there are 3,568 fewer high-risk cases or a $1.4 \%$ reduction. When vaccination starts in September with rollout speeds of 2 and 3, there are 1,995 fewer high-risk cases or a 1.5\% reduction and 8,248 fewer high-risk cases or a $9 \%$ reduction, respectively, when compared to no prioritization. The reduction in hospitalizations as a consequence of the vaccine prioritization schemes is also observed at weekly vaccination rollout speeds of 2 and 3. When looking at hospitalizations within the high-risk population, who is the group that is more likely to get severe complications, the multi-staged prioritization of elderly and high-risk individuals performs the best (up to 687 fewer high-risk hospitalizations or up to an $8 \%$ reduction when the rollout speed is 2 and up to 1,491 fewer high-risk hospitalizations or up to a $13 \%$

Page $7 / 10$ 
reduction when the rollout speed is 3 , compared to no prioritization). Prioritization of only the elderly does not reduce hospitalizations compared to no prioritization.

The performance of the prioritization policies for deaths does not follow the general pattern we observed for infections and hospitalizations where no prioritization generally performs better. We observe significant reductions in deaths when prioritizing elderly and high-risk individuals since those populations have a higher probability of developing complications and dying, while hospitalizations only depend on age. No prioritization is the worst-performing strategy at reducing overall deaths and deaths among high-risk individuals. When vaccination starts in December and the vaccination rollout speed is 1, two-staged prioritization results in the fewest number of overall deaths and deaths among high-risk individuals ( 411 fewer overall deaths or a $7 \%$ reduction in overall and high-risk deaths compared to no prioritization). When the vaccination rollout speed increases to 2 and 3 , multi-staged prioritization is the best at reducing overall deaths and deaths among high-risk individuals (up to 1,030 fewer deaths or up to a $24 \%$ and a $26 \%$ reduction in overall and high-risk deaths, respectively, compared to no prioritization). For non-high-risk individuals, there are no significant differences in the number of resulting deaths when following two-staged or multi-staged prioritization. When vaccination starts in September, multi-staged prioritization remains the best strategy at reducing overall deaths and deaths among high-risk individuals at all vaccination rates (up to 472 fewer deaths or up to a $21 \%$ and a $24 \%$ reduction in overall and high-risk deaths, respectively, compared to no prioritization.)

The results show that the ranking of the prioritization schemes depends on the vaccination start date, subpopulation evaluated, rollout speed, and outcome considered. Therefore, policymakers should consider factors related to vaccine deployment when choosing a vaccine prioritization scheme. However, another critical factor to consider is the additional burden that vaccine prioritization can have on the system that might result in delays in getting people immunized. Having no vaccine prioritization, i.e., opening vaccination to every adult regardless of age, reduces the spread of the pandemic by limiting infection but results in a higher number of deaths, especially among the elderly and high-risk population. While the prioritization of the vaccination of the elderly and high-risk individuals can have a significant impact, especially in reducing hospitalizations and deaths in the overall and high-risk populations, it is important to mention that its benefits might be not be realized fully if the rollout of the vaccine slows down due to logistical, access, and communication barriers, among others.

We ran an alternative scenario [see Supplementary Section B, Additional File 1] where the vaccination start date in two-staged and multi-staged prioritization was pushed a week later compared to no prioritization to illustrate potential delays due to following a prioritization schedule. The results showed that when a delay occurs, no prioritization strictly dominates two-staged and multistaged prioritization for infections and hospitalizations. However, the schemes with prioritization still resulted in lower overall and high-risk deaths than no prioritization for all scenarios. The decrease in deaths due to the prioritization schemes ranges up to $13 \%$, as opposed to $26 \%$ when there were no delays. For example, when the vaccine starts in December with a rollout speed of 3 , no prioritization results in 4,295 overall deaths and 3,757 high-risk deaths, while multi-stage prioritization results in 3,265 overall deaths and 2,768 high-risk deaths (a $24 \%$ decrease in overall deaths and a $26 \%$ decrease in high-risk deaths). In the case that vaccines are delayed by one week due to prioritization logistics, multi-stage prioritization results in 4,000 overall deaths and 3,419 high-risk deaths. Even with the week delay, multi-stage prioritization results in 295 fewer overall deaths (a 7\% reduction) and 338 fewer highrisk deaths (a $9 \%$ reduction).

The findings of this study show that multi-staged prioritization performs better, reducing hospitalization and deaths when compared to two-staged prioritization, especially at a rollout speed of 2 or 3 . However, two-staged prioritization only requires the allocation of vaccines prioritizing the elderly as opposed to multi-staged prioritization that also requires allocation by risk group, and therefore implies greater coordination efforts. It is important to ensure that incorporating a staggered vaccination rollout by age and risk factors does not impair the vaccine rollout speed.

African-Americans, Hispanics, and native Americans have been at disproportionate risk for COVID-associated illness, hospitalization, and death since the beginning of the pandemic largely due to greater risks of exposure due to inequitable social determinants of health and access to medical care [20]. It may be useful in future models to consider how equitable vaccine promotion and access would impact hospitalizations and deaths.

The results of the impact of prioritization of elderly and high-risk individuals during vaccination rollout can be applied to vaccine distribution across the US; however, results depend on the prevalence of elderly and high-risk individuals in the population studied. 


\section{Conclusion}

Opening vaccination to the adult population regardless of age simplifies vaccine rollout and reduces infection spread but results in a higher number of deaths, especially among the elderly and high-risk population. Elderly and high-risk population prioritization during the vaccine rollout results in fewer high-risk hospitalization and overall and high-risk deaths than no vaccine prioritization. Incorporating the prioritization of the elderly and then high-risk population over prioritizing only the elderly provides a benefit in reducing hospitalizations and deaths; however, such benefits might not be realized fully as vaccine eligibility criteria might be harder to communicate, and the vaccine distribution might slow down. The approach taken to evaluate staged approaches could be useful for a variety of other (non-vaccine) interventions in the setting of an acute crisis where key interventions are in short supply.

\section{Declarations}

Ethics approval and consent to participate: All methods were carried out in accordance with relevant guidelines and regulations.

Consent for publication: Not applicable.

Availability of data and materials: The datasets generated during and/or analyzed during the current study are available from the corresponding author on reasonable request. All data used was publicly available in U.S. Census Bureau American Community Survey (https://www.census.gov/newsroom/press-kits/2019/acs-1year.html), U.S. Census Bureau Census Transportation Planning Products (https://ctpp.transportation.org/ctpp-data-set-information/), Georgia Department of Public Health COVID-19 Daily Status Report (https://dph.georgia.gov/covid-19-daily-status-report) and Georgia Department of Public Health Covid-19 Vaccine Dashboard (https://experience.arcgis.com/experience/3d8eea39f5c1443db1743a4cb8948a9c), and model parameters used are provided in Supplementary Section A, Additional File 1.

Competing interests: The authors declare that they have no competing interests.

Funding: This work was supported in part by the William W. George endowment and the following benefactors at Georgia Tech: Andrea Laliberte, Joseph C. Mello, Richard "Rick" E. \& Charlene Zalesky, and Claudia \& Paul Raines. This work was also supported in part by Cooperative Agreement number NU380T000297 from The Centers for Disease Control and Prevention (CDC) and Council of State and Territorial Epidemiologists (CSTE), an National Science Foundation (NSF) grant to support the high performance computing facilities at Georgia Tech, which were used for the computational runs (MRI 1828187), and research cyber infrastructure resources and services provided by the Partnership for an Advanced Computing Environment (PACE) at Georgia Tech. The funders played no role in the study design, data collection, analysis, interpretation, or in writing the manuscript and the study does not necessarily represent their views.

Authors' contributions: All authors contributed equally to this work.

Acknowledgements: The authors of this paper are thankful to state of Georgia representatives, including Garry McGiboney from Georgia Department of Education, Laura Edison from Georgia Department of Public Health, and Susan Miller and Natalie Lee from Georgia Geospatial Information Office for their support, guidance, or sharing data sources. The authors are also thankful to Zihao Li, Arden Baxter, John Asplund, Nicoleta Serban, Melody Shellman, Hannah Lin, Ethan Channel, Pravara Harati, April Zhuoting Yu, Gabriel Siewert, and Christopher Stone for supporting various parts of the projects.

\section{References}

1. The COVID-19 Vaccine Priority Line Continues to Change as States Make Further Updates [https://www.kff.org/policywatch/the-covid-19-vaccine-priority-line-continues-to-change-as-states-make-further-updates/]

2. The Advisory Committee on Immunization Practices' Interim Recommendation for Allocating Initial Supplies of COVID-19 Vaccine - United States, 2020 [https://www.cdc.gov/vaccines/hcp/acip-recs/vacc-specific/covid-19.html]

3. Feds Shift COVID-19 Vaccine Focus to People 65 and Over or With Underlying

Conditions [https://www.aarp.org/health/conditions-treatments/info-2021/65-and-older-coronavirus-vaccines.html] 
4. National Academies of Sciences, Engineering, and Medicine: Framework for equitable allocation of COVID-19 vaccine. 2020.

5. Opinion: We need a better way of distributing the covid-19 vaccine. Here's how to do

it. [https://www.washingtonpost.com/opinions/2021/01/12/covid-19-vaccine-distribution-needs-be-radically-simplified-heres-howdo-it/]

6. Georgia Department of Public Health: COVID-19 Vaccination Plan. In.; 2021.

7. Maine Adopts Age-Based Approach to Expanding Vaccine Eligibility [https://www.maine.gov/governor/mills/news/maineadopts-age-based-approach-expanding-vaccine-eligibility-2021-02-26]

8. Altevogt BM, Nadig L, Stroud C: The 2009 H1N1 influenza vaccination campaign: summary of a workshop series: National Academies Press; 2011.

9. Skrip LA, Galvani AP: Next Steps for Ebola Vaccination: Deployment in Non-Epidemic, High-Risk Settings. PLOS Neglected Tropical Diseases 2016, 10(8):e0004802.

10. Guttieres D, Sinskey AJ, Springs SL: Modeling Framework to Evaluate Vaccine Strategies against the COVID-19 Pandemic. Systems 2021, 9(1):4.

11. Ferranna M, Cadarette D, Bloom DE: COVID-19 Vaccine Allocation: Modeling Health Outcomes and Equity Implications of Alternative Strategies. Engineering (Beijing) 2021:10.1016/j.eng.2021.1003.1014.

12. Bubar KM, Reinholt K, Kissler SM, Lipsitch M, Cobey S, Grad YH, Larremore DB: Model-informed COVID-19 vaccine prioritization strategies by age and serostatus. Science 2021, 371(6532):916-921.

13. Chapman LAC, Shukla P, Rodríguez-Barraquer I, Shete PB, León TM, Bibbins-Domingo K, Rutherford GW, Schechter R, Lo NC: Comparison of COVID-19 vaccine prioritization strategies. medRxiv 2021:2021.2003.2004.21251264.

14. Chen J, Hoops S, Marathe A, Mortveit H, Lewis B, Venkatramanan S, Haddadan A, Bhattacharya P, Adiga A, Vullikanti A et al: Prioritizing allocation of COVID-19 vaccines based on social contacts increases vaccination effectiveness. medRxiv 2021:2021.2002.2004.21251012.

15. Rosenstrom E, Mele J, Ivy J, Mayorga M, Patel M, Lich KH, Johnson K, Delamater P, Keskinocak P, Boyce R et al: Can Vaccine Prioritization Reduce Disparities in Covid-19 Burden for Historically Marginalized Populations? medRxiv 2021:2021.2007.2027.21261210.

16. A Timeline of Covid19 Developments in $\mathbf{2 0 2 0}$ [https://www.ajmc.com/view/a-timeline-of-covid19-developments-in-2020]

17. Keskinocak P, Oruc BE, Baxter A, Asplund J, Serban N: The impact of social distancing on COVID19 spread: State of Georgia case study. PLoS One 2020, 15(10):e0239798.

18. U.S. Census Bureau: American Community Survey, 2018 American Community Survey 1-year Estimates. In.: U.S. Census Bureau; 2018.

19. People with Certain Medical Conditions [https://www.cdc.gov/coronavirus/2019-ncov/need-extra-precautions/people-withmedical-conditions.html]

20. Tai DBG, Shah A, Doubeni CA, Sia IG, Wieland ML: The Disproportionate Impact of COVID-19 on Racial and Ethnic Minorities in the United States. Clinical Infectious Diseases 2020, 72(4):703-706.

\section{Supplementary Files}

This is a list of supplementary files associated with this preprint. Click to download.

- AdditionalFile1.docx 